\title{
DEVELOPMENT OF TARGET COST FOR A HIGH-PERFORMANCE BUILDING
}

\author{
Atle Engebø ${ }^{1}$, Olav Torp ${ }^{2}$, and Ola Lædre ${ }^{3}$
}

\begin{abstract}
Target costing aims at making both cost and value to drivers for design. Still, few have studied how this is done in a high-performance building project, where a set of parameters beyond the typical cost, schedule, and quality parameters are optimised. Here we explore how a construction project team collaborated to reach the owner's allowable cost during design using observations and document study. The findings show that the owner should precisely describe expectations before starting Target Value Design. If not, the owner will get disengaged or develop suspicion towards provided cost estimates. Furthermore, we argue that the typical development of expected cost can inhibit a high-performing design team. The expected cost typically starts at the owner's allowable cost, increases drastically during design, and has to be substantially reduced. The consequence is that a highperforming team's mood moves from optimism towards realism and eventually into a realm where challenges occur. The domain where challenges arise is when the project team must substantially reduce the expected cost to reach an acceptable level. To remain high-performing throughout, the project team should avoid a drastic increase in expected cost in the initial stages.
\end{abstract}

\section{KEYWORDS}

Target cost, Target Value Design, collaboration, team development.

\section{INTRODUCTION}

A project delivery method, as defined by Miller et al. (2000), is "a system for organizing and financing design, construction, operations and maintenance activities that facilitates the delivery of a goods or service". Previously, traditional project delivery methods such as design-bid-build and construction management at risk were a preferred choice for project owners. The latest years, collaborative project delivery methods with early contractor involvement (Lloyd-Walker and Walker, 2015; Fischer et al., 2017; Engebø et al., 2020b; Wondimu et al., 2020) and Target Value Design (TVD) (Ballard and Reiser, 2004; Ballard and Pennanen, 2013; Do et al., 2015) have received increased attention. Successful application of TVD in construction has been reported (e. g. Ballard and Reiser, 2004; Ballard and Pennanen, 2013; Denerolle, 2013) However, some TVD projects experience final costs that exceed target costs (Ballard et al., 2015; Tillman et al., 2017).

$\mathrm{PhD}$ candidate, Norwegian University of Science and Technology (NTNU), Trondheim, Norway, +47 905719 02, atle.engebo@ntnu.no, orcid.org/0000-0002-5293-0176

2 Associate Professor, Norwegian University of Science and Technology (NTNU), Trondheim, Norway, +47 934226 73, olav.torp@ ntnu.no, orcid.org/0000-0002-1916-5097

3 Professor, dr. ing., Department of Civil and Environmental Engineering, The Norwegian University of Science and Technology (NTNU), ola.ladre@ntnu.no, orcid.org/0000-0003-4604-8299 
For successful application, realistic performance requirements and target cost should be set before conceptual design (Tanaka, 1990).

In Target Costing, the cost is estimated directly from the owner's requirements before design rather than from a design offered to satisfy those requirements (Pennanen and Ballard 2008). According to (Ballard, 2006; Ballard, 2007), the target cost can equal the owner's allowable cost set in the project business plan before hiring the contractor, or it can equal the expected cost defined by the project team. The expected cost would be the facility's cost, with a determined performance, if provided at current best practice. The contractor's target cost (target selling price) is often set right below or at the allowable cost, while if the project team defines the expected cost, the owner often sets the target cost at the expected cost.

Current best practice refers to a situation where the project team participants set target costs that are stretch goals and share risk and reward with the owner. If setting target cost equal to the owner's allowable cost, the project team must assess if the requirements can be met when taking acceptable risk. The owner can combine a mutually agreed target cost with risk and reward sharing. Some researchers claim that the target cost should be lower than the allowable cost for both project alliancing and Integrated Project Delivery (Sakal, 2005; Fischer et al., 2017). Torp (2019) has studied how public agencies in Norway set cost targets. In Norway, both the Norwegian Public Roads Administration and Statsbygg (the Norwegian government's principal advisor in construction and property affairs) use steering targets lower than the allowable cost. The target cost can change during design, and in some projects, the owner has an option to fund design before making a Go/No Go decision for the actual construction. Applications of collaborative project delivery methods with TVD are not much studied in Norway, so this paper answers the following research questions:

1. How is target cost set on a high-performance building project?

2. How does expected cost develop through the collaborative phase?

3. How can a collaborative delivery method contribute to development of expected cost?

\section{LITERATURE REVIEW}

The project delivery method dictates how the project team engages, methods used, and how different actors get involved. Regardless of the project delivery method, the design is conducted by a multi-disciplinary team of designers seeking to fulfill the project owners' requirements. This paper is limited to so-called collaborative project delivery that seeks to integrate and align the actors in an early stage, i.e., already in the planning phase (Fischer et al., 2017). This sort of collaboration is challenging as the team assembled is both multi-disciplinary and inter-organisational. Another distinction is that the planning phase typically involves a high degree of uncertainty and an equally high degree of flexibility (Knotten et al., 2017).

\section{The Concept: Target Costing and TARget Value Design}

The method of target costing stems from Japanese Manufacturing companies and may be described as a management technique aimed at reducing life-cycle costs of new products, while ensuring quality, reliability, and other consumer requirements, by examining all possible ideas for cost reduction at the product planning, research and development, and the prototyping phases of production (Kato, 1993).

Guilding et al. (2000) refer to Target Costing as a practice that seeks to satisfy a customer need by setting a reasonable target cost is for that need. Target costing is 
implemented primarily during the development and design phases of the manufacturing process as a system designed to improve an organization's services and related processes through cost optimization (Sobotka et al., 2007). An often-used approach in traditional Design-build is a fixed-price contract. A more 'innovative' approach is the cost-plus approach, where the owner pays all of the project's audited costs plus some fee. The fee may be fixed, an incentive, or an award fee (Griffis and Butler, 1988). A difference between cost-plus with incentives for cost reduction and target cost is that cost-plus reduces cost by lowering performance, quality, and profit.

In contrast, design and customer input guides cost reduction in target cost. Cost-plus can, for example, leads to squeezing of the sub-contractors. Suppose target cost is reduced below allowable cost by pressing the sub-contractors' overhead, rather than changing the scope of design or customer input. In that case, this undercuts any motivation for the subcontractors to lower the total cost (Nicolini et al., 2000). Instead, the object of target costing is to identify the production cost of a product so that, when sold, it generates the desired profit margins (Cooper, 2001). Consequently, the project team should emphasise proper cost management throughout the whole design process. The process should be centered around identifying the allowable cost at which the contractor can produce the product with a predefined and acceptable overhead. Then breaking the target cost down and have the suppliers find ways to deliver the components at the set target cost while still making a profit margin (Cooper, 1997; Cooper and Slagmulder, 1999).

Target Value Design (TVD) is a management practice in which the design and construction are steered towards the project constraints while maximizing customer value (Ballard, 2011). TVD can be implemented through various project delivery methods, and research suggests that TDV can be applied to projects of all sizes (Do et al., 2014). TVD was adopted from Target Costing (TC). Target Value Design focuses on setting targets, design to targets and builds to targets (Zimina et al., 2012). The allowable cost is a cost the customer finds acceptable; i.e., they are willing and able to pay that amount and are assured that they will receive in return what they want. The project owner sets allowable costs, and the expected cost is estimated several times during design and construction, as output from the cost model, estimated by the project team.

\section{The Process: The Relational Side - InTegrated Team}

This paper concentrates on the design stage, as this phase is crucial for defining the project's value. Yet how the process is run varies vastly from project to project; for example, value engineering (VE) revolves around searching for alternative components that fulfill the component's function by an alternative method. The concept is centered around function analysis to identify low-cost products without reducing quality but remove unnecessary costs and improving design through workshops that focus on highcost areas concerning the particular design (Palmer et al., 1996).

In collaborative project delivery methods with Early Contractor Involvement (ECI), the early stages of the project are centered around the notion of integrated design. Work is organised around multidisciplinary teams, whose members are often co-located to favour collaboration and innovation (Forgues et al., 2008). A way of organising the design is by engaging all involved representatives concurrently (Concurrent Engineering) and where all life cycle stages of the product are considered simultaneously, from the conceptual stage through to the detailed design stage (Love and Gunasekaran, 1997).

A key element to this approach is that one needs the multidisciplinary team to perform from an early stage and onward. Tuckman's model suggests that groups progress through 
four classified stages (Tuckman, 1965). Tuckman later revised his model, adding a fifth stage called adjourning (Tuckman and Jensen, 1977). The starting point called forming is constituted by orientation, testing, and establishing dependency. The second stage is storming, where conflict and polarization around interpersonal issues occur and serve as resistance to group influence and task requirements. In norming stage, this resistance is overcome, and the group feeling and cohesiveness develop, new standards evolve, and new roles are adopted. Lastly, the performing stage is reached in which the interpersonal structure becomes the tool of task activities. Roles become flexible and functional, and group energy is channelled into the task (Tuckman, 1965; Tuckman and Jensen, 1977). To contextualise, teamwork is one of the most critical features in the success of a good design process and to fulfill the project owners' requirements (Freire and Alarcón, 2002). Thus, using a framework such as the Tuckman model as a lens to understand how teams develop during a design process could be valuable in discussing group dynamics in the context of Target Value Design.

While the model is broadly accepted within various fields, providing a breadth of application for viewing different practical settings, contemporary sources have noted that the model does not sufficiently recognise the complexity of group dynamics or the many specialised areas of group development. Group dynamics also includes leadership, motivation and rewards, and external factors such as organizational roles, resource allocation, and external stakeholders' pressure (Bonebright, 2010).

\section{METHODOLOGY}

The empirical findings stem from an observational study and a document study of the design phase, the so-called contract phase 1, of a high-performance building located in Trondheim, Norway. The findings are merged with insight gained from a thematic literature review on Target Costing, Target Value Design, and Group Development.

The studied high-performance building is a Zero Emission Building (ZEB) Laboratory in Norway. This 4 stories high building contains approximately $2000 \mathrm{~m}^{2}$, where a set of parameters beyond the typical cost, schedule and quality is optimised. When finished, it will be a full-scale laboratory where the users are exposed to different temperatures, air qualities, moisture levels, luminosities etc. The first reason for selecting this high-performance building is that the complexity made it challenging to estimate expected cost and define cost targets. The second reason is that experiences from collaborative project delivery methods with TVD are easier to transfer from complex to non-complex projects than the other way around.

To collect data, the main author observed the weekly full-day ICE-sessions (from 08:30-15:00) where the owner and the contractor-led project team participated for nearly half a year. The observations were part of a larger research project on collaborative project delivery methods in construction projects. The data presented in this paper are observations that resulted in a dataset of more than hundred pages of fieldnotes.

Normally, around twenty people attended the weekly ICE-sessions. The project team included five participants from the contractor (Project manager, Estimation manager, Design manager, BIM-coordinator, and one assistant), seven from the owner (Project manager, Project coordinator, Laboratory-representative, user-representative, and three ZEB-experts), three from the architect (Head-architect, assistant-architect, and LCAExpert), and four from the sub-contractors (HVAC, Automation, Construction, and Electrician). The project team was informed about the intentions of the observations, and after a couple of weeks the presence of the observer felt natural. 
Also, the researchers had access to a webserver with project documentation, including contracts and project specifications. Documents describing the development of expected cost during the design and from a discourse between the owner and the contractor regarding how they described Target Value Design were of particular interest. However, the study did not implement any specific tool for reporting the change in moods of the project team. Thus, the description of how the team developed through the design phase represents the perception and analysis of the empirical evidence collected by the observing researcher.

\section{FINDINGS AND DISCUSSION}

We have studied a project that used a two-step model where the first step started with the owner contracting a contractor together with an architect, consultants, and subcontractors to a development phase (contract phase 1). The development phase usually has a preliminary target price and an option for a turnkey contract with a target price in step two (contract phase 2), provided that the parties manage to develop an adequate project. The first contract was a Norwegian Standard contract (NS 8402: For consultancy commissions with remuneration based on actual time taken) supplemented with a "Partnering Agreement" drafted and signed by all parties involved. The first contract regulated the schematic design, where the contractor continuously updated the expected cost. The project team was assembled through a start-up seminar from the contract signing and subsequently worked together through 22 weekly Integrated Concurrent Engineering Sessions and workshops.

The case (The ZEB laboratory) was a "high-performance building" (HPB) with a set of ambitions beyond the typical cost, schedule, and quality parameters. The challenge was to design a building that fulfilled the particular demands: (1) to achieve ZEB-COM level (simulated in a 60 years perspective), (2) to have separate control and measurement systems, one for ordinary operation and one for research, (3) design flexible energy and climatization systems, (4) design flexible workspaces, (5) build a façade that enabled rebuilding and adaption, for example to future climate changes (Time et al., 2019).

\section{How Target Cost is Set in a High-Performance Building Project}

The project's complexity made the owner opt for a collaborative project delivery method where key actors' were involvement early on and put together in a high-performance team that could provide technical solutions and innovations to produce the full-scale laboratory facility. Through the project delivery method, the owner emphasised relational aspects instead of just transactional. However, as the owner loosened up transactional regulations, the need for trust, shared goals, and follow-up by management increased (Engeb $\emptyset$ et al., 2020a). The project team started with just the ambitions laid out by the owner and the predefined allowable cost. The parties had to agree on a schematic design with an expected cost at- or below the allowable cost to proceed to the second phase. Thus, after phase 1, the owner had an option (but not an obligation) to procure the project team for detailed design and construction (contract phase 2) using a Norwegian Standard DesignBuild contract (NS 8407: for design and build contracts).

The allowable cost was set at 127 million NOK by the three funding parties (a university, a research organisation, and the Norwegian Research Council). Thus, throughout phase one, the project team evaluated the expected cost against the design. The challenge was to develop the design, adding value for the customer while at the same time keeping the expected cost down. The project team developed the design in the ICE 
sessions. The sessions were designed to optimise iteration between the sub-contractors (technical specialists), the architect, the contractor, and the owner. Typical design iterations started with the architect presenting the current BIM model before the subcontractors gave technical feedback, and the main contractor considered consequences for the expected cost. After sessions in the plenum, the team continued work in thematic groups (indoor design, outdoor design, and technical).

\section{How Expected Cost Develops Through the Collaborative PHASE}

Initially, the ICE-sessions proved to be a suitable means for balancing the design and managing the expected cost. The sub-contractors, the architect, and the owner representatives discussed, decided, and changed solutions in the ICE sessions. However, a transparent estimation of consequences for the expected cost was more challenging to incorporate. Using the previous ICE-session inputs, the contractor estimated and updated the expected cost before the next ICE session. This practice led the owner to perceive the estimation of consequences for expected cost like a "black box" as they only saw the input (design iteration in an ICE session) and output (updated costs in the next ICE session). In other words, the owner had little or no insight into the contractor's actual cost-estimation process, as illustrated in figure 1.

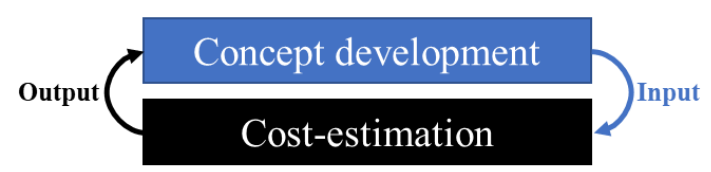

Figure 1: The cost estimation process seen from the owner perspective.

In theory, this should not be a problem as the participants meet jointly to reveal and revise their estimates before presenting an itemised list to the complete project team, including the owner. Although the owner attended those meetings and had access to the books (open book), it was not transparent how the contractor calculated the numbers and what they included. Therefore, the owner wanted to review the cost estimate. The contractor's hourly rates, material prices, and calculated overhead were of particular interest. The same was valid for the sub-contractors contingencies and overhead and whether the main contractor had added an overhead. The owner suspected that the contractor added overhead or contingencies onto the detailed cost items, and overhead included in the expected cost. The owner meant that the contractors should only include overhead once and not in "several layers.".

The degree of detail and the accuracy of the expected cost will typically increase as the schematic design progresses, as decisions are made, and more information is known. The contractor estimated the expected cost continuously during schematic design, and stretch-goals were built into the target cost to provide an incentive for cost savings when the owner and main contractor signed the design and build contract. The owner was decisive on the ambitions related to ZEB-COM, separate control, measurement systems, etc., and had to accept a reduced number of total square meters in the building during the iterations in schematic design. This way, the owner and contractor could agree on a target cost - as it should be according to TVD - lower than allowable cost (AC).

Figure 2 shows how the estimated expected cost developed through phase 1 of the case project. At the start of the schematic design, Positivism roamed. As the contractor started developing the project and assessing all the uncertainties, the expected cost surged (Expected Cost 1). Viewing the initial stages in the light of Tuckman's model, we can see 
the expected cost escalate through the forming and storming stages as the team has a positive attitude and at the same time seeks to avoid conflicts or themes that create tensions ("positivism roams"). At some point in the collaboration, realism takes hold of the project team as the project team reached the norming and performing stages. At this point (expected cost 2), the target cost has further increased because the contractor changed the estimation technique from rough element calculation to more detailed item calculation. It was unclear whether the increase in expected cost was caused by too-low initial pricing of the elements or the project team had added other qualities(too much emphasise on value-adding during the initial stages of the collaboration). The change in estimation technique also caused the owner to lose track since the estimates became detailed and too extensive for outsiders to comprehend. The subsequent cost reduction led by the owner and contractor seemed to remind the sub-contractors of a process that focuses on lowering specifications, reducing quality, which undercuts any motivation to lower the total cost (Nicolini et al., 2000). They felt that the main contractor tried to squeeze their profits in front of the owner. Therefore, the lowering of expected cost below allowable cost was an inhibitor to collaboration for the sub-contractors.

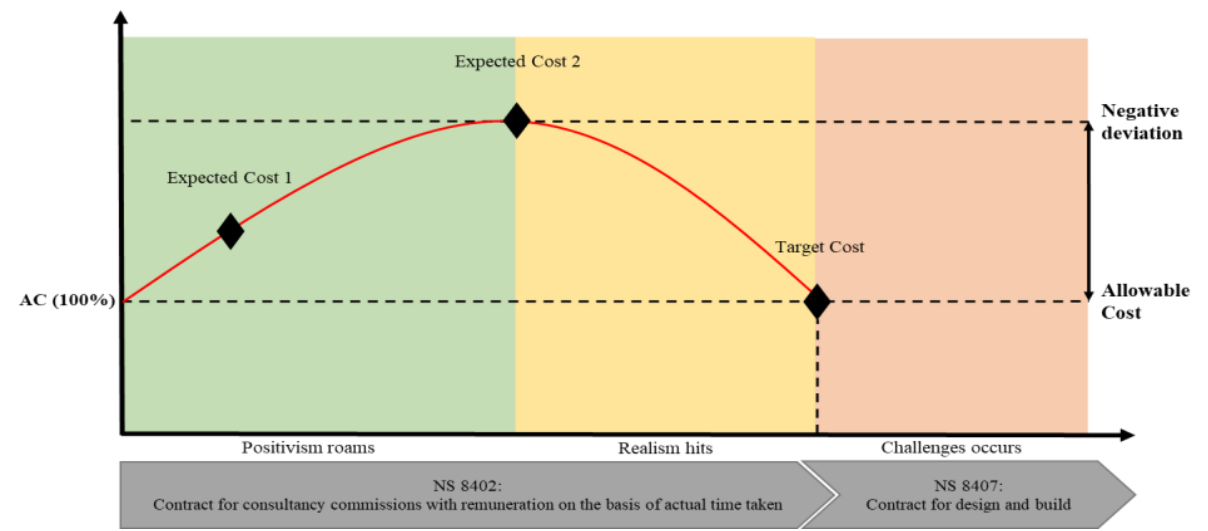

Figure 2: Conceptual presentation of the expected cost development.

Towards the end of the first phase, the expected cost travelled downward towards the allowable cost. The project team had to move away from concentrating on value-adding in the design towards strict cost-cutting instead. The contractor and the owner agreed upon a Target Cost that both parties could live with (but neither were utterly content with). The parties then signed the contract for phase 2 (detailed design \& construction). Even though the owner and contractor agreed on a target cost after cost-cutting, they still seemed to have different perceptions of what was included and which party was responsible for the uncertainty. The total overhead included in the target cost was $15 \%$, and they added a risk contingency of approximately $1 \%$ to the individual cost items. Consequently, despite a pleasant first part of the collaboration, the different perceptions of the target cost may cause problems during phase 2 (challenges occur).

\section{How a Collaborative Delivery Method Contributes to DEVELOPMENT OF EXPECTED COST}

Regarding the third research question - about how TVD can contribute to developing target cost - the owner and main contractor agreed on a target cost developed during the collaborative schematic design after a halting TVD process. As described in the literature, a potential downside of traditional design and build contracts is that the design concentrates on cost reduction by reducing performance, quality, and profit - not with 
design and customer input - and that undercuts any motivation for the subcontractors to lower the total cost (Nicolini et al., 2000). This cost-cutting by pure reduction of performance, quality, and profit is unwanted in TVD. Instead, the collaboration should result in innovative solutions for materials and systems that reduce costs while maintaining functions according to the owner's initial specifications. Furthermore, practicing open-book was supposed to support TVD, but the practice deviated from the theory. While the project team shared both model updates and cost estimate updates in the Big Room meetings, the contractor estimated expected costs between the ICE sessions.

Consequently, it became challenging for the owner to evaluate the estimate's basis and unclear if, for example, the estimates were reduced by lowering performance or as a result of design or customer input. The owner was given weekly summaries and spreadsheet overviews, but the owner had to physically access the contractor's computers located at their headquarter for detailed insight. The owner had been able to access estimates, neither on the web-hotel nor physically. This lack of transparency might catalyse the need for reviewing the build-up of the cost estimate. Additionally, the subcontractors delivered their estimations to the main contractor, who included them in the owner's summaries. As documented in a similar case study, unclear descriptions of how the open book is practiced represent a potential weakness (Larssen et al., 2019).

Lean practitioners on both the owner and contractor sides should be aware that teams do evolve over time and that this development could affect the target value design process. However, one lesson is that the actors - to avoid relational challenges - must agree on both the scope and the target price before they enter the implementation phase.

\section{CONCLUSIONS}

This paper reports from the design process (contract phase 1) of a high-performance building. A contractor-led project team collaborated with the owner to reach a target cost corresponding to the owner's allowed cost. The team consisted of the main contractor, the architect, and sub-contractors. The team got a set of ambitions from the owner beyond the typical cost, schedule, quality parameters, developed design, and the corresponding expected cost. In phase 2, the owner and main contractor will sign a design and build contract based on the schematic design and the set target cost.

The development of the expected cost is illustrated in Figure 3. It derailed from the allowable cost quite early, in a realm of positivism where the actors introduced innovative technical solutions to add as much value as possible to the high-performance building. Seeing this in light of how teams develop, we can say that the team went from optimism (forming and storming) towards realism (norming and performing) when the project team put a more considerable emphasis on the expected cost. The managers changed from supporting playfulness towards stressing costs and assessing risks resulting in disagreements in the team, which corresponds well with the norming stage.

Target Value Design's benefits could have increased in the investigated case if the owner had communicated the ambitions more precisely. When the project team started to reduce expected cost 2 to a level corresponding to the owner's allowable cost, the mood changed from positivism to realism. The owner wanted to review the expected cost, while the contractor and the sub-contractors had to remove overhead and risk contingencies they felt entitled to. When the mood changed, the collaboration in the high-performing team of specialists cooled down.

This paper's contribution is the illustration of how the expected cost and the mood of the actors developed. More studies are needed to make sure that cost reduction in TVD 
projects is achieved by design and customer input and not by reducing performance, quality and profit.

\section{REFERENCES}

Ballard, G. 2006. "Rethinking Project Definition in Terms of Target Costing". 14th Annual Conference of the International Group for Lean Construction, 2006/01/01 Santiago, Chile. Santiago, Chile, 77-89.

Ballard, G. 2007. Target costing in the construction industry. Presentation in P2SL 2007 Conference. Berkeley, California.

Ballard, G. 2011. "Target value design: current benchmark". Lean Construction Journal, 6, 79-84.

Ballard, G., Dilsworth, B., Do, D., Low, W., Mobley, J., Phillips, P., Reed, D., Sargent, Z., Tillmann, P. \& Wood, N. 2015. "How to make shared risk and reward sustainable". Proc. 23rd Ann. Conf. of the Int'l. Group for Lean Construction. 257-266.

Ballard, G. \& Pennanen, A. 2013. "Conceptual estimating and target costing". Proc. 21th Annual Conference of the International Group for Lean Construction (IGLC), 2013/07/31 Fortaleza, Brazil. 31-2.

Ballard, G. \& Reiser, P. 2004. "The St. Olaf College Fieldhouse Project: a case study in designing to target cost". Proc. 12th Annual Conference of the International Group for Lean Construction (IGLC), 2014/08/03 Helsingør, Denmark. 234-249.

Bonebright, D. 2010. "40 years of storming: a historical review of Tuckman's model of small group development". Human Resource Development International, 13, 111-120.

Cooper, R. 1997. Target costing and value engineering, New York, Routledge. doi.org/10.1201/9780203737378.

Cooper, R. \& Slagmulder, R. 1999. "Develop profitable new products with target costing". MIT Sloan Management Review, 40, 23.

Denerolle, S. 2013. The application of Target Value Design to the design phase of 3 hospital projects, Project Production Systems Laboratory, University of California, Berkeley

Do, D., Ballard, G. \& Tillmann, P. 2015. Application of Target Value Design in the Design and Construction of the UHS Temecula Valley Hospital: part 1 of 5 . University of California, Berkeley: Project Production Systems Laboratory. 231-245.

Do, D., Chen, C., Ballard, G. \& Tommelein, I. D. 2014. "Target value design as a method for controlling project cost overruns". Proc. 22nd Annual Conference of the International Group for Lean Construction (IGLC), Oslo, Norway. 171-181.

Engebø, A., Klakegg Ole, J., Lohne, J. \& Lædre, O. 2020a. "A collaborative project delivery method for design of a high-performance building". International Journal of Managing Projects in Business.

Engebø, A., Lædre, O., Young, B., Larssen, P. F., Lohne, J. \& Klakegg, O. J. 2020 b. "Collaborative project delivery methods: a scoping review". Journal of Civil Engineering and Management, 26, 278-303.

Fischer, M., Ashcraft, H. W., Reed, D. \& Khanzode, A. 2017. Integrating Project Delivery: A Simple Framework for Putting IPD into Action, Wiley Online Library.

Forgues, D., Koskela, L. \& Lejeune, A. 2008. "Breaking Socio-Cognitive Barriers to Value Generation in Integrated Teams". Proc. 16th Annual Conference of the International Group for Lean Construction (IGLC), 2008/07/16 Manchester, UK. Manchester, UK, 435-446. 
Freire, J. \& Alarcón, L. F. 2002. "Achieving Lean Design Process: Improvement Methodology". Journal of Construction Engineering and Management, 128, 248-256.

Griffis, F. H. \& Butler, F. M. 1988. "Case for cost-plus contracting". Journal of Construction Engineering and Management, 114, 83-94.

Guilding, C., Cravens, K. S. \& Tayles, M. 2000. "An international comparison of strategic management accounting practices". Management Accounting Research, 11.

Kato, Y. 1993. "Target costing support systems: lessons from leading Japanese companies". Management Accounting Research, 4, 33-47.

Knotten, V., Lædre, O. \& Hansen, G. K. 2017. "Building design management - key success factors". Architectural Engineering and Design Management, 13, 479-493.

Larssen, P. F., Engebø, A., Lædre, O. \& Klakegg, O. J. 2019. "Contracts and Culture in a Partnering Project". 10th Nordic Conference on Construction Economics and Organization Talinn, Estonia. Emerald Publishing Limited, 49-57.

Lloyd-Walker, B. \& Walker, D. 2015. Collaborative project procurement arrangements, Project Management Institute.

Love, P. E. D. \& Gunasekaran, A. 1997. "Concurrent Engineering in the Construction Industry". Concurrent Engineering, 5, 155-162.

Nicolini, D., Tomkins, C., Holti, R., Oldman, A. \& Smalley, M. 2000. "Can Target Costing and Whole Life Costing be Applied in the Construction Industry?: Evidence from Two Case Studies". British Journal of Management, 11, 303-324.

Palmer, A., Kelly, J. \& Male, S. 1996. "Holistic Appraisal of Value Engineering in Construction in United States". Journal of Construction Engineering and Management, 122, 324-328.

Sakal, M. W. 2005. "Project alliancing: a relational contracting mechanism for dynamic projects". Lean Construction Journal, 2, 67-79.

Sobotka, A., Czarnigowska, A. \& Skibniewski, M. J. 2007. "Target costing in public construction projects". Proc. 9th International Conference Modern Building Materials, Structures and Techniques, Vilnius, Latvia. 16-18.

Tanaka, M. 1990. "Topics in target costing in Japanese companies". Genka Keisan,(Special Issue), 28, 43-65.

Tillman, P., Do, D. \& Ballard, G. 2017. "A Case Study on the Success Factors of Target Value Design". Proc. 25th Annual Conference of the International Group for Lean Construction (IGLC), 2017/07/9 Heraklion, Greece. 9-12.

Time, B., Engebø, A., Christensen, M., Dalby, O. \& Kvande, T. 2019. "The design process for achievement of an office living laboratory with a ZEB standard". IOP Conference Series: Earth and Environmental Science, 352, 012053.

Torp, O. 2019. "How Stochastic Cost Estimates Could Be Applied in Relation to Target Value Design". Proc. 27th Annual Conference of the International Group for Lean Construction (IGLC), 2019/07/03 Dublin, Ireland. Dublin, Ireland, 595-606.

Tuckman, B. W. 1965. "Developmental sequence in small groups". Psychological bulletin, 63, 384-399.

Tuckman, B. W. \& Jensen, M. A. C. 1977. "Stages of small-group development revisited". Group \& Organization Studies, 2, 419-427.

Wondimu, P. A., Klakegg, O. J. \& Lædre, O. 2020. "Early contractor involvement (ECI): ways to do it in public projects". Journal of Public Procurement.

Zimina, D., Ballard, G. \& Pasquire, C. 2012. "Target value design: using collaboration and a lean approach to reduce construction cost". Construction Management and Economics, 30, 383-398. 